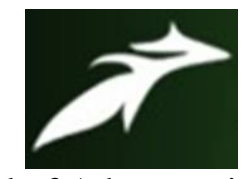

S. Kiruthika et al, International Journal of Advances in Agricultural Science and Technology,

Vol.8 Issue.1, January-2021, pg. 125-131

ISSN: 2348-1358

Impact Factor: 6.057

NAAS Rating: 3.77

\title{
FABRICATION OF SOLAR BASED POWER SPRAYER FOR AGRICULTURE- A REVIEW
}

\author{
S. Kiruthika ${ }^{1}$; C.M. Kavin Prabhu ${ }^{1}$; T. Nishanthi ${ }^{1}$; G. Karunya ${ }^{1}$ \\ UG students, Department of Agriculture Engineering, Nandha Engineering College, Perundurai, Erode, \\ Tamil Nadu, India ${ }^{1}$ \\ Dr. S.Vanitha ${ }^{2}$ \\ Associate Professor, Department of Agriculture Engineering, Nandha Engineering College, Perundurai, \\ Erode, Tamil Nadu, India ${ }^{2}$ \\ DOI: 10.47856/ijaast.2021.v08i1.016
}

\begin{abstract}
In agricultural sector generally farmer uses traditional way of spraying pesticides and insecticides is done by farmers, carrying backpack type sprayer on shoulder to spray. Which requires more human effort, costly and consume time efficiency and it causes human risk. The above problems can be solved our power sprayer. Sprayers are mechanical devices that are specifically designed to spray liquids quickly and easily. This study articulates solar operated spray pump for agriculture purpose. This type of sprayer covers large area and easy to operate. A solar sprayer typically consists of a tank for carrying the liquid to be sprayed, here we use solar panel which converts heat energy into electrical energy that stores into the battery, motor is for pumping out of liquid in tank, spray nozzles on automatically disperse the liquid in a downward direction over an considerable area, a chassis is mounted on the wheels and hose is attached for spraying. The device is mechanically pushed from behind and as the supply to the pump is switched on, the liquid is sprayed. Giving attention to these important problems an attempt is made to develop equipment which will be beneficial to the farmer for the spraying operations. This study focused on solar based power sprayer for spraying operation. This type of sprayer reduced spraying time, human effort and cost.
\end{abstract}

Keywords: Solar panel, Battery, Sprayer, Chassis 


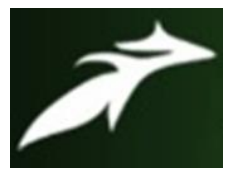

S. Kiruthika et al, International Journal of Advances in Agricultural Science and Technology, Vol.8 Issue.1, January-2021, pg. 125-131

ISSN: 2348-1358

Impact Factor: 6.057

NAAS Rating: 3.77

\section{INTRODUCTION}

In our country farming is done by traditional way, besides that there is large development of industrial and service sector as compared to that of agriculture. The spraying is traditionally done by labor carrying backpack type sprayer which requires more human effort. To overcome the above two problems, we have tried to eliminate these problems and designed the equipment which will be beneficial to the farmer for the spraying operations. From time immemorial, the sun has been the prime source of energy for life on earth. The solar energy was being used for the purposes like drying clothes, curing agricultural produce, preserving food articles, etc. Solar energy is virtually inexhaustible. The total energy we receive from the sun far exceeds our energy demands. For human development in many countries there is research and trials are going on the solar energy and the wind energy, but in our country, manpower is available in large proportion. So we make our solar based power sprayer in this process, we lifts water in tank for spraying on the agricultural products or on small plants in lawns and gardens. Pesticide should be limited where possible, but when necessary, use them responsibly. Always read and follow the pesticide label instructions before applying, such as with insecticides or herbicides, to Reduce the risk of exposing humans or non- target animals. To protect the environment, which includes the proper use of pesticides to prevent contamination of water resources.

\section{REVIEW OF LITERATURE}

Sukhatme,S.P., in 2001 the study of handbook of solar energy has been generating electricity from solar energy, through the photovoltic and thermal routes. On the whole, India has made significant effort for the successful utilization of solar energy .

R.Joshua et.al in 2010 has fabricated solar sprayer- an agriculture implement energy demand and its one of the major thread for our country. According to them, application of non-conventional energy is the only alternate solution for conventional energy demand.

Samuel Gan-Mor et.al in 2012 have done recent developments in sprayers for application of bio pesticides an overview. Transition from the optimized conditions of a laboratory experiment to the harsh conditions experienced in the field has so far proved more difficult for application of bio pesticides in contrast to chemicals. This has undoubtedly been due to lack of investment in the development of effective formulations and delivery systems, in order to commercialized more potential bio pesticides. The relatively small effort invested in target- specific sprayers, compared with the investment in laboratory studies, has led to unbalanced development, and example the need for closer integration between formulation and engineering research. The challenge is to get effective formulations so that biological control agents can be easily applied by farmers.

Sandeep.H. Poratkar et.al in 2013 has Developed multi-nozzle pesticide sprayer pump, they suggested model has removed the problem of back pain, since there is no need to carry the tank on the back. This model has more number of nozzles which will cover maximum area of spraying in 


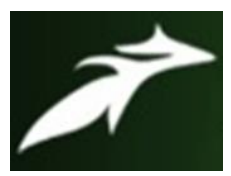

S. Kiruthika et al, International Journal of Advances in Agricultural Science and Technology, Vol.8 Issue.1, January-2021, pg. 125-131

ISSN: 2348-1358

Impact Factor: 6.057

NAAS Rating: 3.77

minimum time \& at maximum rate. Muscular problems are removed an there is no need of operate the lever.

Sanjay.S et.al in 2015 has designed and fabrication of mechanical pest sprayer.thus the low cost manually operated mechanical pesticide spraying machine the spraying in terms of reduction in work and reduce in using energy, thus our tool provide a good pest killing technique.

Akshay, M.N et.al in 2016 has designed and fabrication of solar operated sprayer for agricultural purpose and this inventional is about an agricultural pesticide sprayer, which uses solar energy as source of power for spraying.

M.A.Gaodi et.al in 2016 has described that there are many types of sprayers and spraying machine are available in market. Both are having difference with type of operation and working principle .these types are created as per the quantity of forms and level of reduce the human effort with economically. Conventional methods and advance technologies both are available in it. Advance technologies more advantages than conventional methods.

R.D.Gorle et.al in 2016 have fabricated automatic pesticide spraying machine, there are many types of pesticides sprayers are available. But mostly use is backpack sprayer, which is cheaper and less maintenance. It requires lot of time and high operating cost. By the electric components like motor, pump and spraying nozzles the process of spraying comes economically. The automatic pesticides spraying machine covers more area than conventional machines.

Faijubhai malek in 2016 has devoloped mechanically operated cart for pesticide sprayer for agriculture. This project about a pesticide sprayer mounted on a cart which is operated mechanically without any external source of energy. The handle of the sprayer will be mechanically operated through the rotating of the shaft of the wheels of the cart using an efficient of the mechanism. This will give uniform spraying for the farm. The efficient design for the farmers will reduce their effort drastically.

Siddharth kshirsagar in 2016 has Designed and developed the agriculture vehicle sprayer, their motive behind developing this equipment is to create mechanizations which will to minimize effort Of farming. It is suitable for the spraying at minimum costs for the formers so that he can afford it, of the many product available. The sprayer is are metered to allow quick mixing and the coarse sprays, so it does not takes as long apply weeds killers, insecticides etc,.

K.Akhilesh et.al in 2016 has designed and worked of adjustable manual push operated pesticide spraying machine, it is found that the existing pesticide spraying machine use petrol and diesel to run. It can cause pollution and further vibration produced in the machine cause noise pollution while probable hand held machine may cause health problems for a person as he directly contact with insecticide. The machine can work very effectively with respect to covering area, time and cost of a spraying process. 


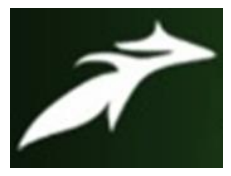

S. Kiruthika et al, International Journal of Advances in Agricultural Science and Technology, Vol.8 Issue.1, January-2021, pg. 125-131

ISSN: 2348-1358

Impact Factor: 6.057

NAAS Rating: 3.77

Vipul jhod et.al in 2016 has designed self powered pesto-sprayer, this equipment has no need of electrical energy, mechanical energy from outsource. It is a self powered equipment. The chain drive is used to transfer the power. Whitworth mechanism translates rotation motion to reciprocating motion.

Dr.R.N.Panchal sir et.al in 2016 has mono wheel operated pesticide spraying machine. This project is an effort to fulfill the entire requirement discussed earlier. The wheel operated reciprocating pump is strictly designed taking into consideration all the mechanical term that are related to design of pump. All the thing are aimed towards the less effort required to operate the pump. The pump is a light duty component capable of sprayed high pressure liquid through nozzle. It reduces man power for operation.

Joshi dhruv bharatbhai in 2017 has Innovated the vehicle moves in forward pump activates and due to it pressure will be generated in the tank and pesticide will be sprayed out from the nozzle. The vehicle will operated by engine in forward direction; therefore no harm effect will occur to human health. Also they concluded a lots of time will be saved for the small scale farmers.

G.H.Raisoni in 2017 has design and fabricated the solar operated agro-sprayer, the newly designed agro sprayer fulfill the tasks like hand spraying. Ic engine spraying and leg pump spraying etc. Using non conventional energy source ie., solar energy. The model is designed to be eco friendly and lower cost, and thus will prove to be more efficient when compared to petrol basic pesticides sprayer. This model is most suitable for small and medium scale farmers.

Dhiraj bhagat et.al in 2017 has design, development and fabrication of manually operated multinozzle pesticide sprayer pump and seed sowing equipment the model has removed the problem of back pain since there is no need to carry the tank on the back bone and shoulder.

Ahalya m et.al in 2017 has designed a solar powered semi-automatic sprayer for use vineyards. They demonstrate project, the implementation of robotics and mechatronics in the field of agriculture. The performance satisfactory under laboratory condition. It gave good coverage and the cost of operation. The safety and long term health of farmers is ensured by eliminating human labour completely from this process.

Krishna murthy et.al in 2017 has fabricated the solar pesticide sprayer, they build solar powered pesticides pumping system is cost effective comparatively to an electrically operated hydraulic pump. Since here non-conventional energy is used to achieve the required head. This device serve its purpose to some extent, but proper course of actions, it can perform still better. Which cover maximum area of spraying minimum time at maximum rat .imported hollow cone nozzle should be used in the field for better performance.

Rohit. L.G. in 2017 has design cam operated agrochemical pesticide sprayer. Agriculture sector is 


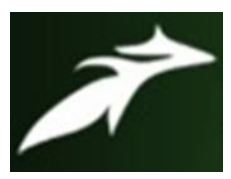

S. Kiruthika et al, International Journal of Advances in Agricultural Science and Technology, Vol.8 Issue.1, January-2021, pg. 125-131

ISSN: 2348-1358

Impact Factor: 6.057

NAAS Rating: 3.77

required to enhance and increase the productivity of the field crop by using cam operated agrochemical pesticide sprayer. There is no need to carry tank on the back muscular problems are removed and there is no need to operate the lever. This above pump can be used in multiple crops.

Swapnil thorat et.al in 2018 has been developed small scale farmers interested to operate knapsack sprayer because of its versatility, cost and design the multi nozzle pump which will perform spraying at maximum rate in minimum time. The machine is eco-friendly. It is most suitable for small farmers having 5-6acre.it has less time to cover the more area and sprays preciously.

Minakshi dhole et.al in 2018 has reviewed on automatic adjustable techniques in agriculture for pesticides spray, they said that there are many different types of sprayers available in this paper . It is concluded that pesticide spraying machine is main factor in india for development agriculture sector and improve good food productivity. By using of robotics we can reduce the effort of labours and uniform spraying operation. So there is need of low cost robots in agricultural sector especially in

Pesticides spraying machine.

Dhirajaher et.al in 2018 has designed an hand driven four wheel automatic spraying machine, it is a multipurpose machine for spraying chemicals as well as water, and profitable machine for spraying chemicals. For spraying chemicals on crops for protecting them from harmful pesticides $\&$ fungicides. Multi nozzle covers more area at small time period.

U.nainar et.al in 2019 has experimented a investigation at agriculture sprayer and weeder, their equipment is purposely design for the farmers having small farming land say 5-6acre. It is suitable for spraying as well as weeding at minimum cost for the farmer. The equipment will results more beneficial when it is subjected to moist soil for weeding purpose due to moist soil weed cutter can easily penetrate and dig out the soil and hence will easily accomplished the weeding process.

Kumar,K.P et.al in 2019 has designed and fabrication of portable solar operated chemical sprayer. Now a days pesticide sprayer is based on fuel engine and hand operated sprayer. In agriculture, pesticides spraying is the important for protect the crop from insect.

Jarar khokar in 2019 has design mechanical agriculture sprayer vehicle.every farmers spraying using back type sprayer. It is time to begin the modern era in agriculture. Those back type sprayer is not profitable and also time consuming. Overcome this problems mechanism mounted on a vehicle for spraying is introduced which can increase productivity.

Suresh kumar.K et.al in 2020 has been developed an pesticide solar sprayer with charge controller for agriculture needs and the main objective of this project is to spray the chemical using non conventional source of energy. Now a days energy is basic need for all human beings. 


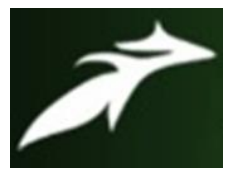

S. Kiruthika et al, International Journal of Advances in Agricultural Science and Technology, Vol.8 Issue.1, January-2021, pg. 125-131

ISSN: 2348-1358

Impact Factor: 6.057

NAAS Rating: 3.77

The alternate solution of this problem is to use non conventional energy.

From all those literature review, we have researched and identified some problems whereas, a back type sprayer consist of nearly 20liters carried by just two adjustable straps. And so constant pumping is also required mandatorily for the sprayer to deliver the fluids in liquid form. This sprayer covers a very small area and required enormous amount of time to spray the entire furrow land. This results farmers are harmfully affected by muscular disorder problem. To overcome all those circumstance, we design power operated sprayer, we suggest a model has removed the problem of back pain, since there is no need to carry the tank on the back bone and shoulders. And muscular problems are Removed and there is no need to operate the lever and it's an economically friendly therefore affordable for all kind of marginal farmers.

\section{Conclusion}

The development of solar based power sprayer is environment eco-friendly, cost efficient, time saving and reduce the human fatigue. This sprayer can be used largely in agriculture field effectively. It can be good option to select for farmer who is economically challenged and facing electrical problems. It doesn't require fuel and also not create air pollution and noise. The solar operated sprayer will help the farmers of those remote areas of place where fuel is not available easily.

\section{REFERENCES}

[1] Sukhatme S.P.,2001.Handbook of solar energy.New Delhi,Tata McGraw-Hill: ISBN 0-07-462453-9.

[2] Kumar, k.s., tejasri, a., srinivas, m., suresh, v., kumar, a.p. And kumar, d.p.,pesticides solar sprayer with charge controller for agriculture needs.

[3] Akshay M.N.and Waghmare,G., 2016.Design and fabrication of solar operated sprayer for agricultural purpose.National Conference on Innovative Trends in Science and Engineering,Vol. 4, No.7.

[4] Joshua R.,Vasu V and Vincent P., 2010.Solar Sprayer - An Agriculture Implement.International Journal of Sustainable Agriculture 2 (1): 16-19.

[5] Kumar, K.P., Akilan, S., Gobinath, M., Gowtham, D. and Guruprasath, M., Design and Fabrication of Portable Solar Operated Chemical Sprayer. International Journal of Research in Engineering, Science and Management Volume-2, Issue-2, February-2019

[6] Ahalya M,Muktha A,Veena M, Vidyashree G, Rehna V J,April 2017. Solar Powered Semi-Automatic Pesticide Sprayer for use in Vineyards. SSRG International Journal of Electronics and Communication Engineering (SSRG- IJECE), volume 4(4), pp-54-57, ISSN:2348-8549.

[7] Dhiraj Bhagat,April 2017.Design, Development and Fabrication of Manually Operated Mutinozzle Pesticide Sprayer Pump and Seed Sowing Equipment.International Journal of Current Engineering and Technology (IJCET), volume 7(2), pp- 641- 645, ISSN:2277-4106.

[8] Dhiraj bhagat, design development and fabrication of manually operated multi nozzle pesticides sprayer pump and seed sowing equipment, International Journal of Current Engineering and Technology.

[9] Dr.R.N.Panchal Sir, Mr.Nikhil Deshmukh, Miss.Poonam Shahapure, Miss. Mrunalini Patil, 


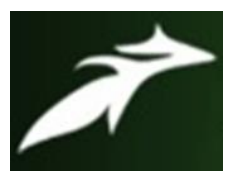

S. Kiruthika et al, International Journal of Advances in Agricultural Science and Technology, Vol.8 Issue.1, January-2021, pg. 125-131

ISSN: 2348-1358

Impact Factor: 6.057

NAAS Rating: 3.77

Miss.Ashwini Kengale,2016.Jspm's Rajarshi Shahu College of Engg, Tathawade pune. Mono wheel Operated Pesticide Spraying Machine.International Engineering Research Journal (IERJ) Volume 2 Issue 3 Page 889-892, ISSN 2395-1621.

[10] Faijubhai Malek, Dipam Patel, Yash Padia, Mit Kundariya, Varun Jarsania, May 2016. Department of Mechanical Engineering, GCET College, VallabhVidyanagar, Gujarat, India. Mechanically Operated Cart for Pesticide Sprayer for Agriculture. International Journal of Innovative Research in Science, Engineering and Technology (An ISO 3297: 2007 Certified Organization) Vol. 5, Issue 5.

[11] Faijubhai Malek, Dipam Patel, Yash Padia, Mit Kundariya, Varun Jarsania, "Mechanically Operated Cart for Pesticide Sprayer for Agriculture", International Journal of Innovative Research in Science, Engineering and Technology (IJIREST), volume5(5), pp-6704-6711, May2016, ISSN:23198753.

[12] Gaodi, M.A., Lonkar, A.S., Wankhede, A.S. and Gandate, S.D., 2016. development of multipurpose sprayer-a review. International Research Journal of Engineering and Technology (IRJET) Volume, 3.

[13] Joshi, D.B., Fabrication of Automatic Agriculture Pesticides Spraying Machine.

[14] Kothari, P.H., Age, H.M., Kathuria, J.A., Bagul, A.A. and Hucche, R.D., 2017. Design and Fabrication of Solar Operated Agro Sprayer. International Journal of Innovative and Emerging Research in Engineering, 4(3), pp.223- 226

[15] Minakshi Dhole, Review on Automatic Adjustable Techniques in Agriculture for Pesticides Spray" Published in International Journal of Trend in Scientific Research and Development (ijtsrd), ISSN: 2456-6470, Volume-3 | Issue-1, December 2018, pp.1269-1272

[16] Poratkar, S.H. and Raut, D.R., 2013. Development of Multinozzle Pesticides Sprayer Pump. International Journal of modern engineering research(ijmer)vol3.

[17] Rajashekhargoud Angadi, Rohit, Satish Changond, Santosh Kagale, January-2017 Mechanical Engineering Department Angadi Institute of Technology \& Management, Belagavi, Cam Operated Agrochemical Pesticide Sprayer. International Journal of Engineering Research \& Technology (IJERT), ISSN: 2278-0181 IJERTV6IS010156 Vol. 6 Issue 01, January-2017.

[18] Ravishkumar Harendra Singh, Abdulhasnain Akodiyawala, Jarar khokar, Ganesh B. Ingole, Trinity Polytechnic, Pune, Maharashtra, Mechanical Agriculture Sprayer Vehicle. International Journal of Advance Research, Ideas and Innovations in Technology.

[19] Samuel Gan-Mor ; Graham A. Matthews, Recent Developments in Sprayers for Application of Biopesticides -an Overview, Biosystems Engineering, Volume 84, Issue 2, 2003, Pages 119-125, ISSN 1537-5110.

[20] Sanjay.S, Sridhar.R, Syed Moinudeen.T, Harshitha.V, "Design and Fabrication of Mechanical Pest Sprayer", International Journal of Innovative Research in Science, Engineering and Technology (IJIRSET), volume 4(10), pp-194-197, August 2015, ISSN: 2319-8753.

[21] Thorat, M.S., Pathare, M.J. and Kumbhar, M.V., 2018. multi-purpose pesticides sprayer pump.

[22] U. Nainar, S. Siva, S. Saravanakumar, S.Sundaresh, A. Vignesh, "Experimental Investigation of Agricultural Sprayer and Weeder", International Journal of Innovative Research in Science, Engineering and Technology (IJIRSET), volume 8(3), pp-2876-2884,March 2019, ISSN:2319-8753.

[23] Vipul Jhod, Akshay Jumle, Saurabh Apte, Ninad Borkar, "Self Powered Pesto- Sprayer", International Journal Of Mechanical Engineering and Technology (IJMET), volume7(2),pp- 300306, April-2016, ISSN:0976-6359. 